\title{
STUDY ON THE STATIC AND DYNAMIC STABILITY OF A MODULAR AIRPLANE SYSTEM
}

\author{
Agnieszka KWIEK \\ Aircraft Design Department, Faculty of Power and Aeronautical Engineering, Warsaw University of \\ Technology, Nowowiejska 24, 00-665, Warsaw, Poland \\ E-mail:11akwiek@meil.pw.edu.pl
}

Received 25 September 2014; accepted 17 July 2016

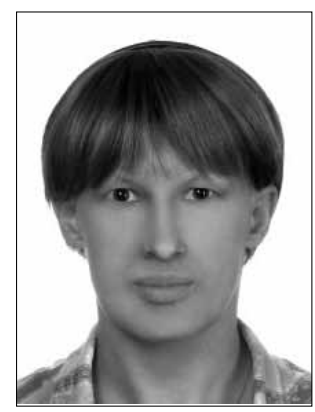

\section{Agnieszka KWIEK}

She received her $B S c$ and $M S c$ degree in aeronautics with the speciality of Airframes at the Faculty of Power and Aeronautical Engineering of Warsaw University of Technology. Since 2011, she is a PhD student of the same university. She was the leader of a Preludium Grant financed by the Polish National Science Centre. She has presented her research results in such conferences as the AIAA Pegasus student conference, the CEAS European Air \& Space Conference (2013), and ICAS (2014). She is an Amelia Earhart Fellow. Her research interests include space technology, aerodynamic and mechanics of flight.

Abstract. The purpose of this research is an analysis of the static and dynamic stability of the Modular Airplane System (MAS). The MAS is designed to perform suborbital space flights. The concept assumes that two tailless vehicles bonded together form a conventional aircraft where the wing of the second one is used as the horizontal tail of the whole system. The CFD calculations, and the stability and control derivatives were conducted by the PANUKL package, which uses a low order panel method for the aerodynamic analysis. The analysis of the static and dynamic stability was performed by the SDSA package. Only the selected part of the MAS mission was investigated. The results that will be presented have been divided into three parts: static stability, longitudinal dynamic stability and lateral dynamic stability.

The MAS has a few possible applications. The first one is a suborbital space tourism flight. Moreover, it can be used as a lunching vehicle for micro satellites or as a testing platform for new space technology to improve their TRL level. Finally, in the far future, it could be used as a fast point-to-point travel system.

The paper presents the results of the static and dynamic stability of a unique aircraft configuration which consists of two tailless vehicles. The research focuses on a situation where the vehicles are just before separation and their mass is similar. Moreover, the influence of the second vehicle's position with respect to the first one is included.

Keywords: static and dynamic stability, space tourism, Modular Airplane System.

\section{Introduction}

Space technology development has caused an increase in the society's interest in space travel. The price of a visit to the International Space Station is about 20 million USD (Furton Corporation 2002). Only a very small group of people can afford such expenses. On the other hand, if the cost of space travel decreased and flight preparations were shorter, the group of potential customers would be quite big (Furton Corporation 2002). Therefore, suborbital flights seem to be a very promising concept. The idea of this kind of flight assumes crossing the boundary of outer space, but the vehicle does not achieve an orbit. The border between the Earth's atmosphere and outer space is at 100 kilometers above sea level, so everyone who has crossed this border becomes an astronaut. Currently, a few companies are working on the first commercial vehicle for a suborbital space flight.

\section{The MAS concept}

Due to the potential demand, a project of designing a new commercial suborbital space vehicle was begun at the Faculty of Power and Aeronautical Engineering at Warsaw University of Technology (Galiński et al. 2007; Figat et al. 2011, 2012). The concept form, referred to as the MAS (Modular Airplane System), consists of two tailless vehicles which are bonded together, thus forming 


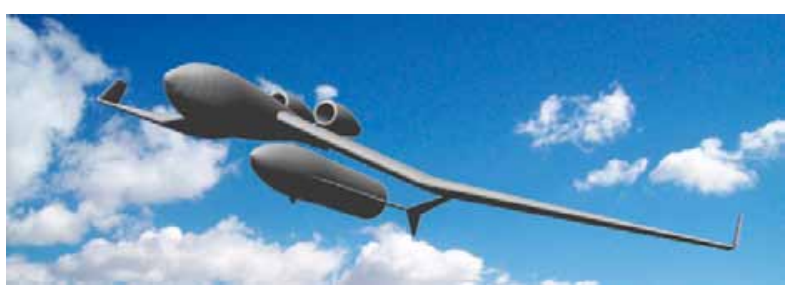

Fig. 1. The Concept of the MAS

a conventional aircraft. The MAS (Fig. 1) includes a Carrier and a Rocket Plane which is used as the tail of the MAS. The Carrier has a sweep wing with winglets and two turbojet engines placed on the top of the fuselage. However, the Rocket Plane is designed for three persons, including the pilot. A hybrid rocket engine is used as the Rocket Plane's propulsion system. Moreover, the concept assumes rotational side plates on the wing tips, which ensure the yawing and pitching channel control. Also, two segmented elevons are used to control the pitching and rolling control channels. One of the most interesting features of the Rocket Plane is a strake which generates additional edge vortices. The concept assumes that the vortex's lift phenomenon is utilized to decrease the sink rate and prevent the structure from overheating during the Rocket Plane's re-entry flight. Since the vehicle is performing a suborbital flight, it means that the initial re-entry speed should be low and the problem of the overheating sharp edge of the leading edge should not occur. The concept of the MAS assumes to use the Rocket Plane's elevons as an elevator to control the pitching channel and obtain trim conditions. The rotational side are used as the rudder of the whole system. The Carrier's elevon is used as the aileron of the MAS.

The MAS mission profile (Fig. 2) assumes the following flight plan:

- the MAS horizontal take off; the Rocket Plane is lifted by the Carrier to about 15 kilometres;

- the vehicles' separation;

- the Carrier's return to the airfield and, at the same time, the Rocket Plane's engine start up and the vehicle's climb start followed by the engine shut down, after which the Rocket Plane continues the mission as a ballistic flight. Finlay, the border between the Earth's atmosphere and outer space is crossed;

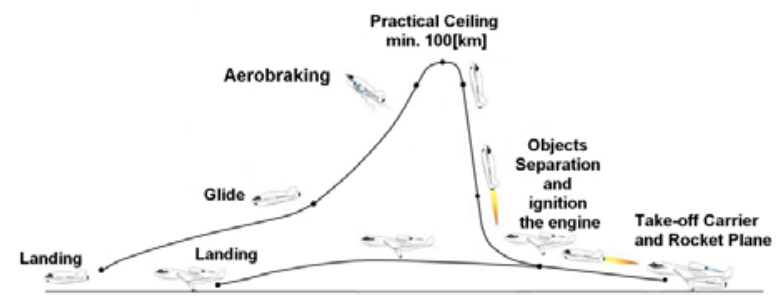

Fig. 2. The MAS mission profile
- the re-entry; during the glide, the mentioned vortex lift phenomenon is generated, which, in turn, reduces the Rocket Plane's rate of descent and prevents the structure from overheating as well;

- the Rocket Plane's landing.

The analysis in this paper is focused only on the bonded configuration just before the vehicles' separation, and the results for different mutual positions of the Rocket Plane relative to the Carrier are presented.

\subsection{Basic data information}

The paper includes the results for two configurations of the MAS. In the first case, the Rocket Plane is closer to the Carrier. Only the distance between the vehicles in direction $\mathrm{X}$ is different. The position of the Rocket Plane in the second case is shifted to the back by $0.537 \mathrm{~m}$. The basic geometrical, mass and performance information are presented in Tables 1 and 2.

Table 1. Basic assumptions of the geometry and performance

\begin{tabular}{lll}
\hline Span & 25 & $\mathrm{~m}$ \\
\hline MAC & 2.359 & $\mathrm{~m}$ \\
\hline Reference area & 55.1 & $\mathrm{~m}^{2}$ \\
\hline Mass before separation & 8766.8 & $\mathrm{~kg}$ \\
\hline Total engine thrust & 27.5 & $\mathrm{kN}$ \\
\hline Altitude & 15 & $\mathrm{~km}$ \\
\hline Separation speed & 155 & $\mathrm{~m} / \mathrm{s}$ \\
\hline $\begin{array}{l}\text { C.G. just before separation } \\
\text { configuration 1 }\end{array}$ & 13.7 & $\mathrm{MAC} \%$ \\
\hline $\begin{array}{l}\text { C.G. just before separation } \\
\text { configuration 2 }\end{array}$ & 22.2 & $\mathrm{MAC} \%$ \\
\hline
\end{tabular}

Table 2. Moment of inertia for both configurations

\begin{tabular}{llll}
\hline Configuration: & No. 1 & No. 2 & \\
\hline Ixx & 89700 & 89700 & $\mathrm{~kg}^{*} \mathrm{~m}^{2}$ \\
\hline Iyy & 59382 & 65381 & $\mathrm{~kg}^{*} \mathrm{~m}^{2}$ \\
\hline Izz & 112476 & 118475 & $\mathrm{~kg}^{*} \mathrm{~m}^{2}$ \\
\hline Ixy & -2720 & -3574 & $\mathrm{~kg}^{*} \mathrm{~m}^{2}$ \\
\hline Izx & -6588 & -8476 & $\mathrm{~kg}^{\star} \mathrm{m}^{2}$ \\
\hline Iyz & -241 & -241 & $\mathrm{~kg}^{*} \mathrm{~m}^{2}$ \\
\hline
\end{tabular}

\section{Aerodynamic and derivatives' calculations}

The stability derivatives were computed by the Panukl package, which uses a low order panel method for the aerodynamic analysis of the potential flow (Goetzendorf-Grabowski 2002). This kind of software can be used in the initial stage of aircraft design. Due to the potential flow, only the linear part of the aerodynamic characteristics can be analysed. The computational model consists of about 10000 elements (Fig. 3). 


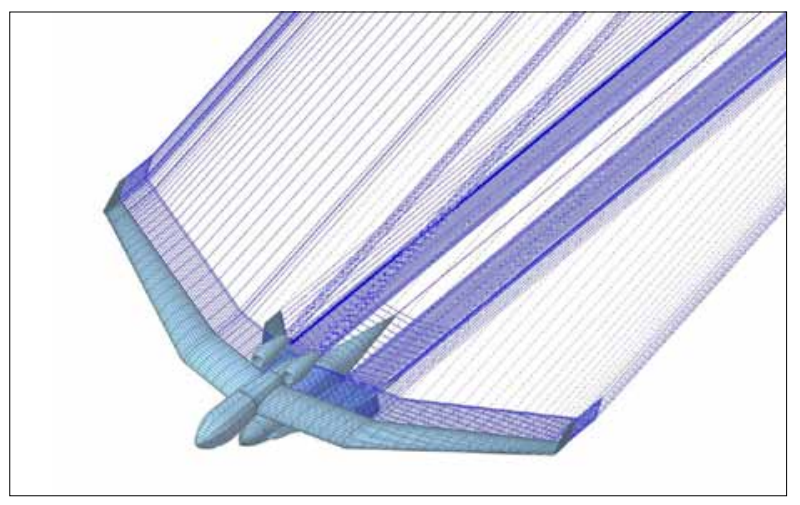

Fig. 3. The computational model (mesh and wake)

The computational model of the Rocket Plane is finished by a cone, but the pressure generated by this cone is not summarized in the total value of forces and aerodynamic moments. Examples of pressure coefficient distributions for both configurations of the MAS are presented in Figure 4.

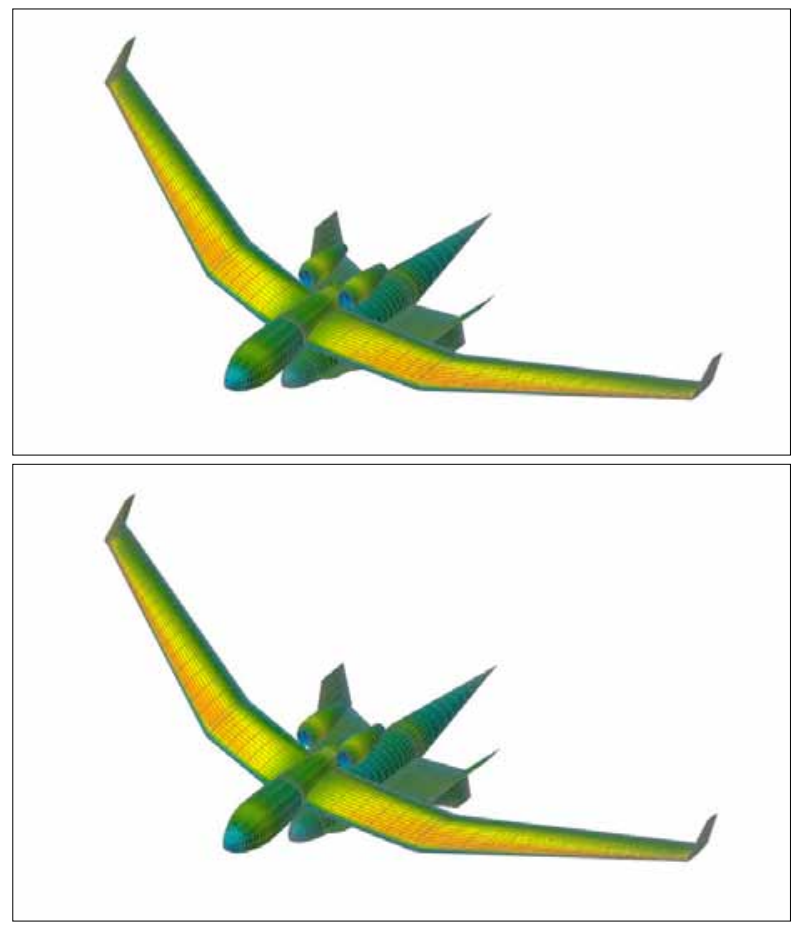

Fig. 4. An example of the pressure coefficient distribution for configuration No. 1 (on the top) and configuration No. 2 (on the bottom) when $\mathrm{Ma}=0.6$ and $\mathrm{AoA}=2$ degrees

The results of the aerodynamic charactersitics computed by Panukl were compared with the results computed by the MGAERO software (see Fig. 5), which uses the Euler cond with a mutligrid acceleration (MGAERO 2005). The model generated by Panukl has a bigger distance between the vehicles in $\mathrm{Z}$ direction as compared to MGAERO; this was limited by the avaible ways of wave generation in the Panukl package. The pressure ceoffiecnt distribution obtained by MGAERO for configration No. 1 of the MAS is presented in Figure 6.

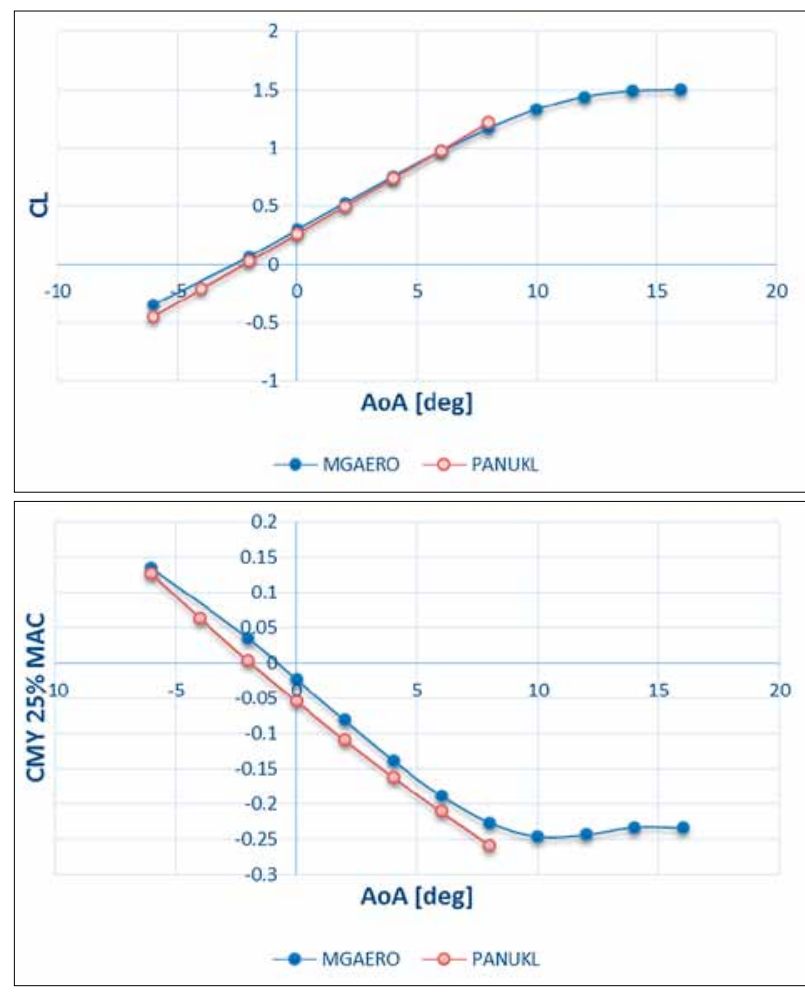

Fig. 5. Comparisons of the lift coefficient and pitching moment coefficient with respect to $25 \%$ of the MAC computed by PANUKL and MGAERO

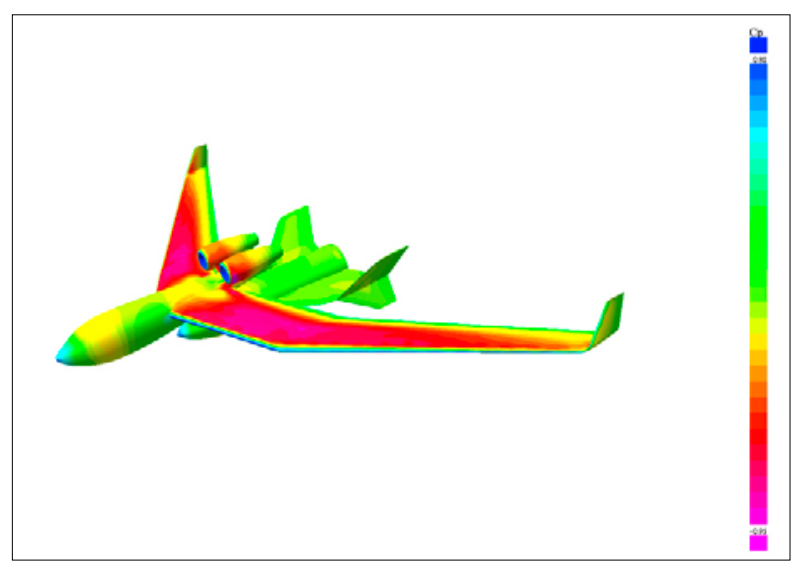

Fig. 6 . The distribution of the pressure coefficient computed by MGAERO when $\mathrm{Ma}=0.5$ and $\mathrm{AoA}=0$ degrees

\section{The static stability analysis}

The first step of the longitudinal static stability analysis is the estimation of the static margin (Nelson 1998). The calculations were made based on the results computed by PANUKL. Moreover, the analysis considers an extreme position of the centre of gravity (take-off being the most rear and just before separation being the most front). The diagrams of the static stability margin versus the Mach number are presented in Figure 7. The solid line represents the results for the centre of gravity just before the vehicles' separation, while the dashed line represents the results for the take-off configuration. The MAS is longitudinally statically stable for both MAS 
configurations and with the considered position of the center of gravity.
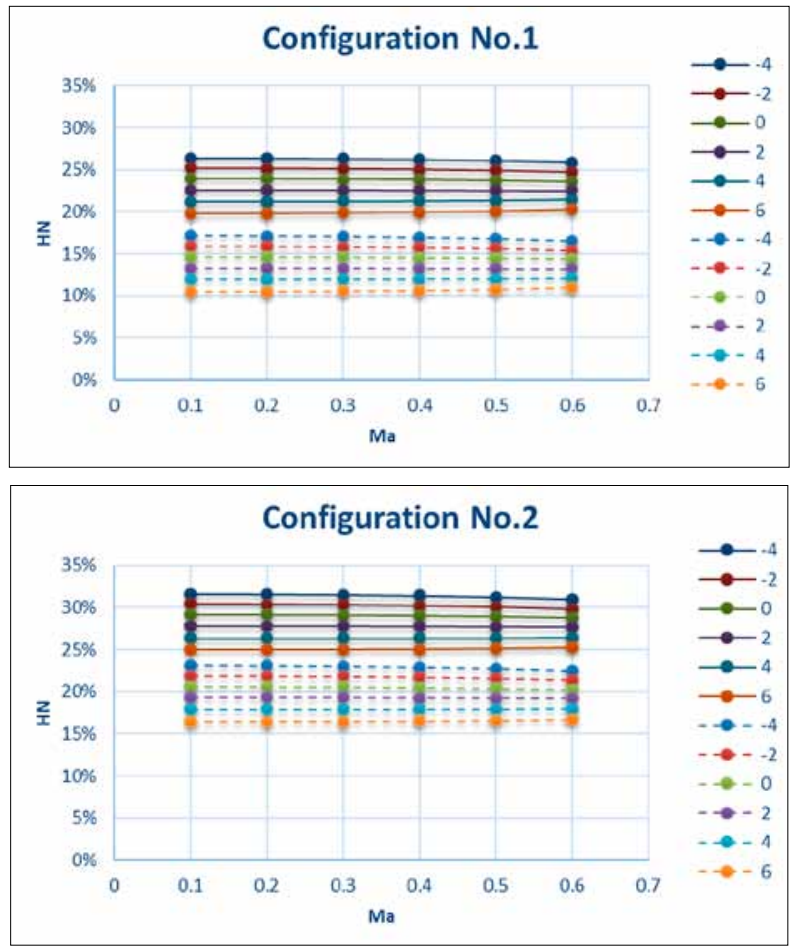

Fig. 7. The static stability margin for configuration No. 1 (on the top) and configuration No. 2 (on the bottom)

The second part of the static stability analysis is the directional static stability. The derivative of the yawing moment with respect to the sideslip angle is presented in Figure 8. The MAS is directionally statically stable for both configurations of the MAS.
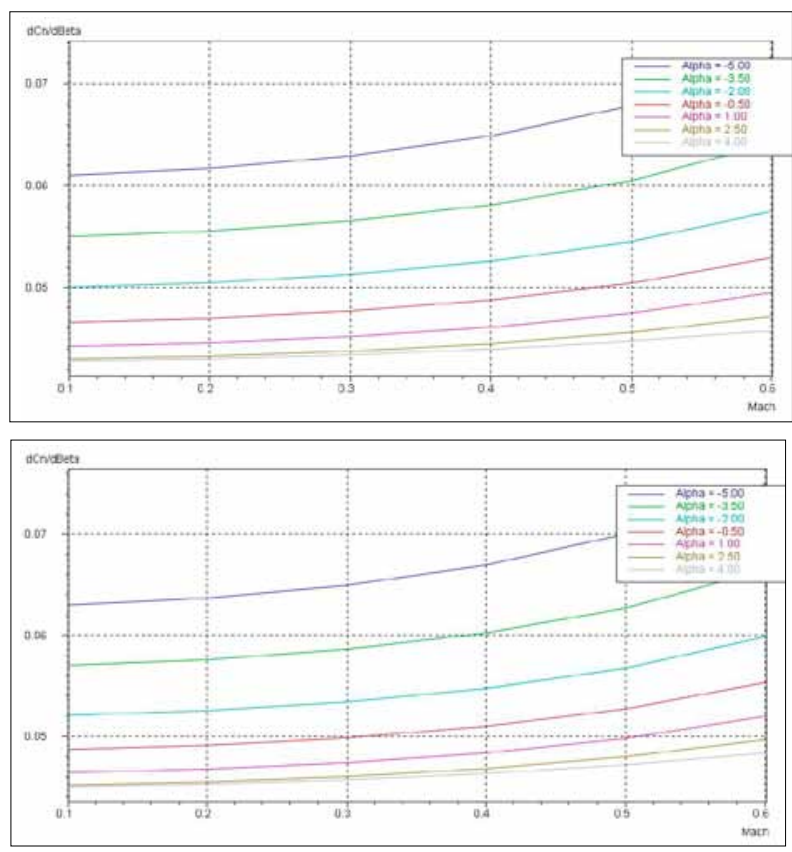

Fig. 8. The derivative of the yawing moment coefficient with respect to the sideslip angle for configuration No.1 (on the top) and configuration No. 2 (on the bottom)

\section{The dynamic stability analysis}

The dynamic stability analysis was performed by the SDSA package (Goetzendorf-Grabowski 2008). The analysis of eigenvalues was made by a linearized nonlinear model (Goetzendorf-Grabowski 2008; GoetzendorfGrabowski et al. 2011) by computing the Jacobian matrix (Goetzendorf-Grabowski 2008; Goetzendorf-Grabowski et al. 2011) around a trim point. Equation (1) presents the general form of the eigenvalue solutions computed by the SDSA package. The damping coefficient and frequency coefficient is computed using equations (2) and (3). The period and time to half damping is defined respectively by Equations (4) and (5).

$$
\begin{aligned}
& \lambda=\xi+i \eta \\
& \omega_{N D}=\sqrt{\xi^{2}+\eta^{2}} ; \\
& \zeta_{d}=\frac{\xi}{\sqrt{\xi^{2}+\eta^{2}}} ; \\
& T=\frac{2 \pi}{\eta} \\
& T_{1 / 2}=-\frac{\ln 2}{\xi},
\end{aligned}
$$

where $\xi$ indicates damping coefficient, $\eta$ - frequency coefficient, $\omega_{\mathrm{ND}}-$ undamping frequency, $\zeta_{\mathrm{d}}$ - damping ratio, $T$ - period, $T_{1 / 2}$ time to half damping.

The first step of the calculations is finding the parameters of the aircraft in the trim condition. The flight parameters in trim for the MAS configuration No. 2 are presented in Figure 9. The analysis was made around the assumed point of vehicle separation which, according to Table 1, has the following parameters: the level of flight is about $15 \mathrm{~km}$ and the separation speed is about $155 \mathrm{~m} / \mathrm{s}$.

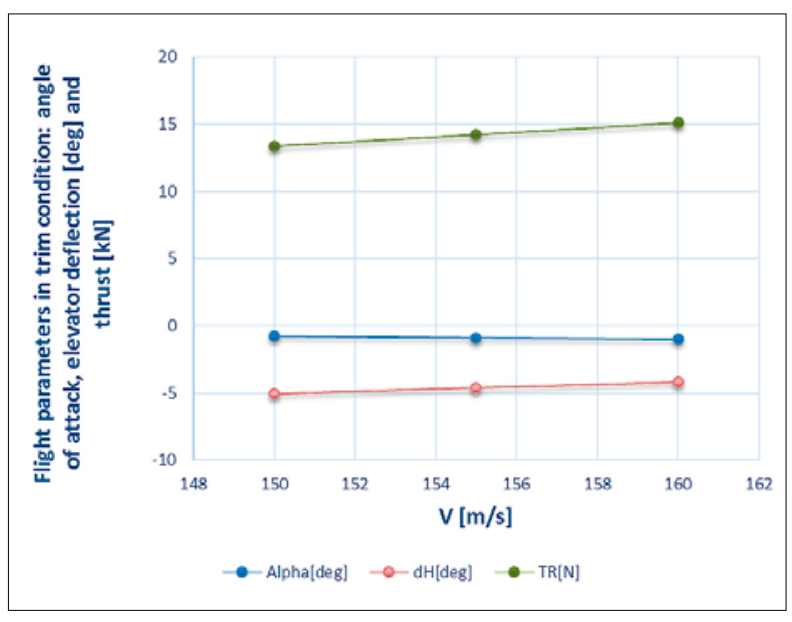

Fig. 9. The flight parameters in trim: angle of attack, elevator deflection and thrust for the MAS configuration No. 2 
The dynamic stability should be assessed using appropriate regulations; however it is difficult to classify the presented vehicle according to current regulations. Therefore, few criterions of stability are included. The results show an influence of the Rocket Plane's position on the MAS dynamic stability.

\subsection{Longitudinal dynamic stability}

The analysis of dynamic stability consist of two parts, the first one is concerned with the longitudinal dynamic stability (phugoid and short period). The result for the phugoid mode for both configurations of the MAS are presented in Figure 10. The MAS is dynamically unstable for configuration No. 1. The stability characteristic for the short period is presented in Figure 11 The period and time to half damping of the phugoid and the short period mode are presented in Figure 12. Base on the MIL regulation (MIL-F-8785C), the short period for both configurations of the MAS is pore damping (Fig. 13).

\subsection{The lateral dynamic stability}

The second part of the dynamic stability analysis is the analysis of the lateral model (dutch roll and spiral). The lateral eigenvalues (for the real and imaginary part) for the dutch roll are presented in Figure 14. Figure 15
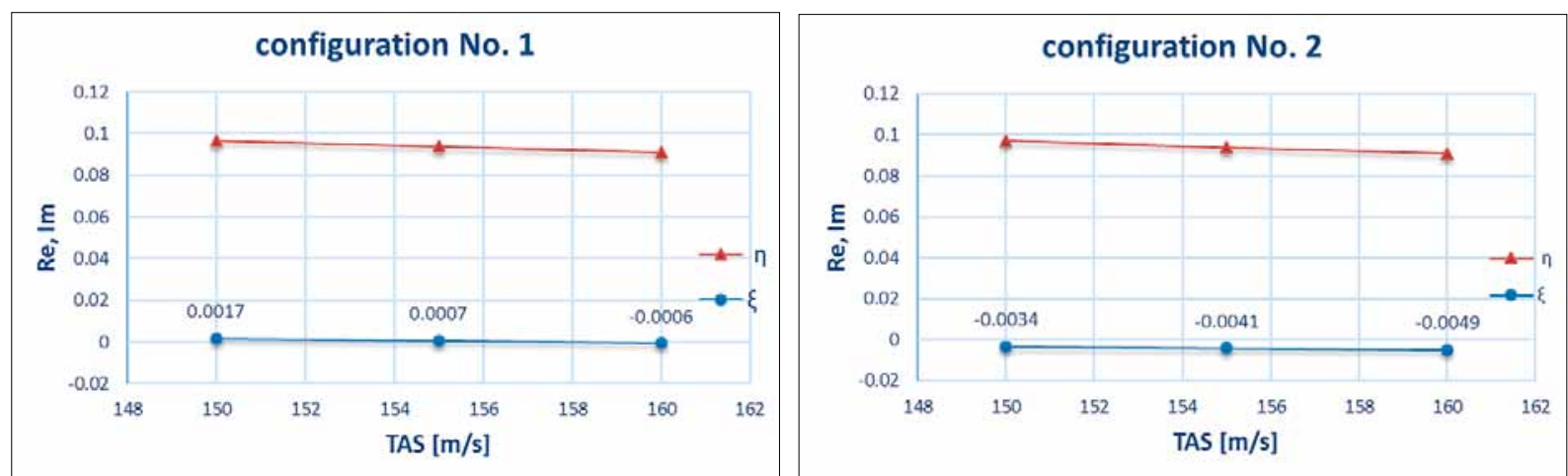

Fig. 10. Eigenvalues of the real and imaginary part for the phugoid
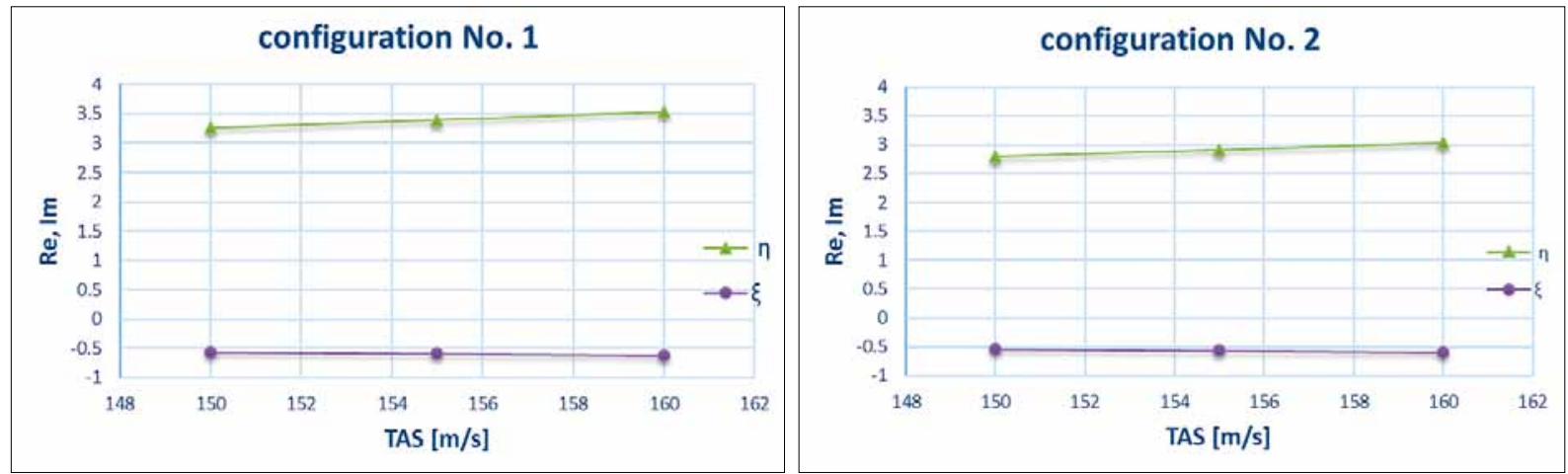

Fig. 11. Eigenvalues of the real and imaginary part for the short period
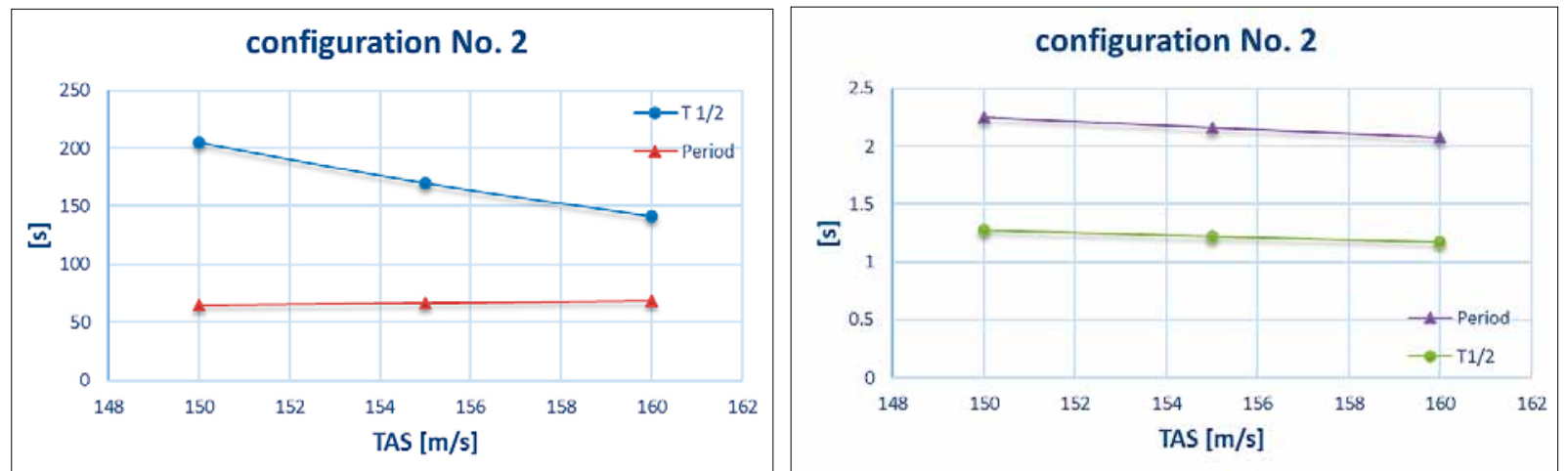

Fig. 12. The period and time to half damping for the phugoid (on the left) and short period (on the right) 

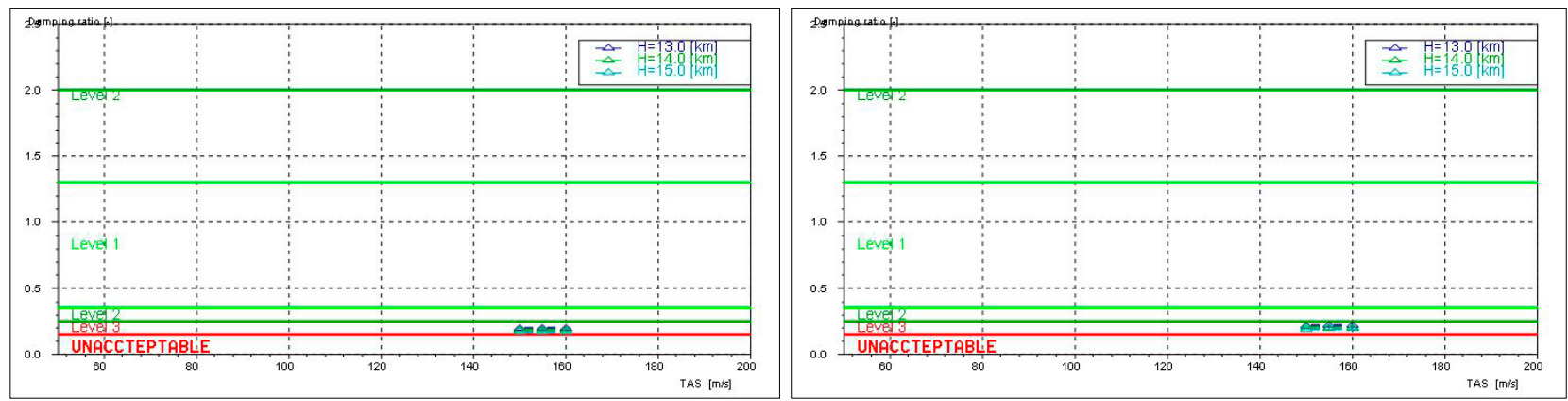

Fig. 13. The damping ratio stability criterion based on the MIL regulation for configuration No. 1 (on the left) and configuration No. 2 (on the right)

presents the period and time to half damping for both MAS configurations for the dutch roll mode. The time to half damping for the spiral mode is presented in Figure 16.

The stability criteria for the dutch roll mode based on the MIL regulation for both MAS configurations are presented in Figure 17. The roll analysis based on the Cooper-Harper pilot assessment for both MAS configurations is presented in Figure 18. The configuration No. 2 has better properties.
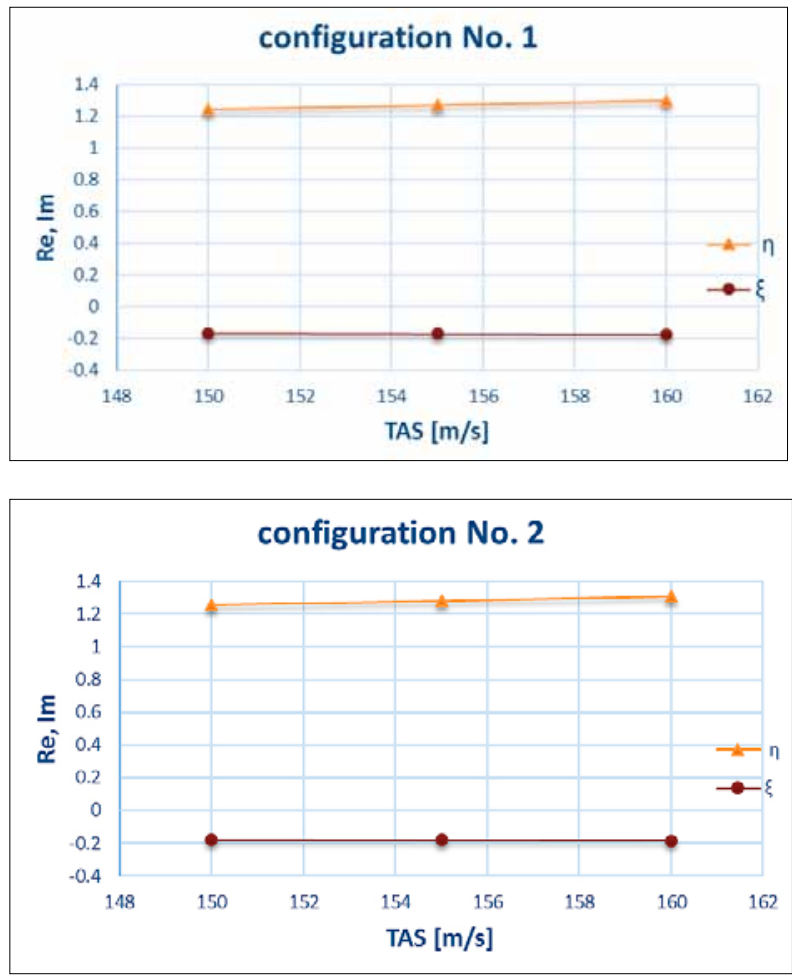

Fig. 14. Eigenvalues for the real and imaginary part for the dutch roll
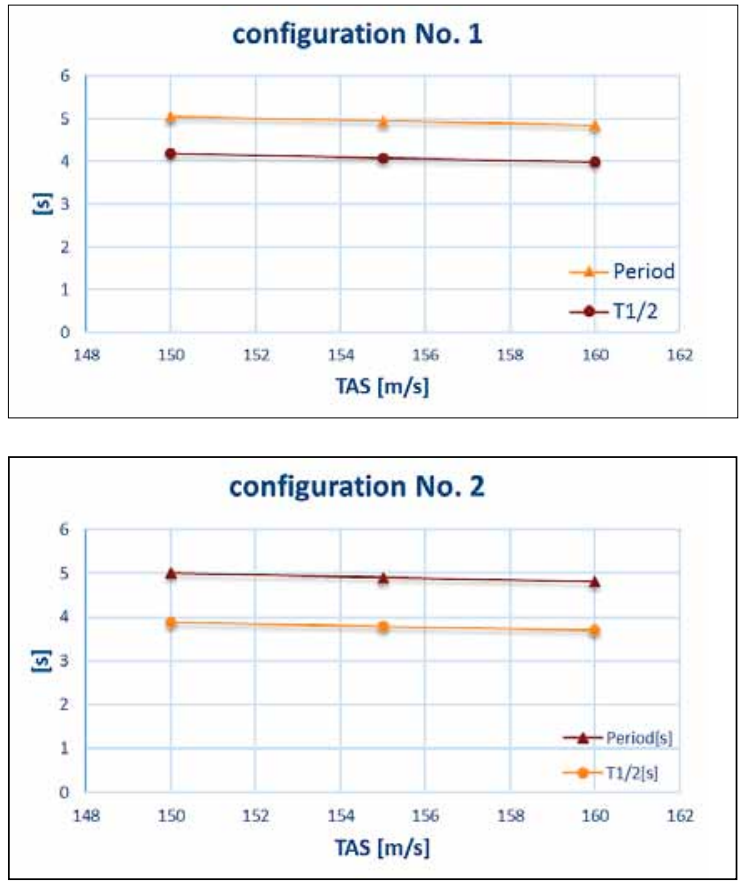

Fig. 15. The period and time to half damping for the dutch roll

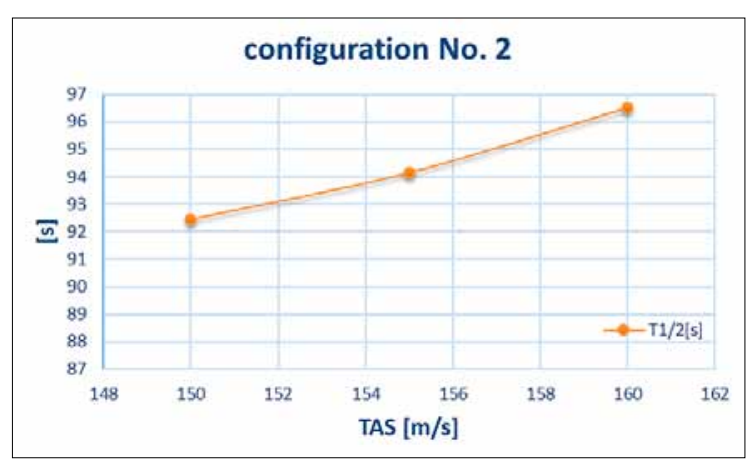

Fig. 16. The time to half damping for the spiral mode 

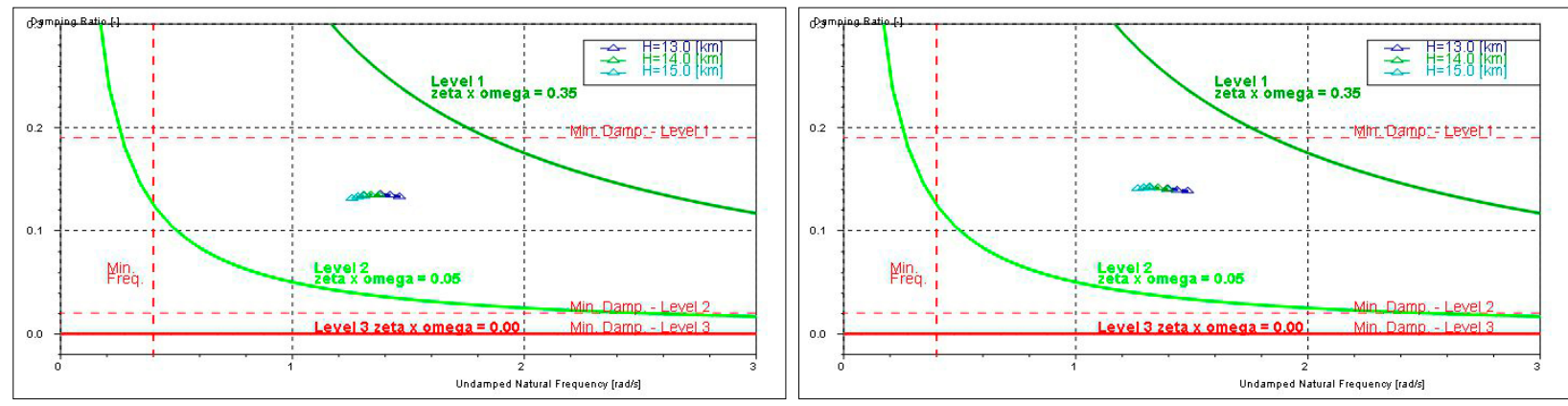

Fig. 17. The damping coefficient for the dutch roll with stability criteria based on the MILfor configuration No. 1 (on the left) and configuration No. 2 (on the right)
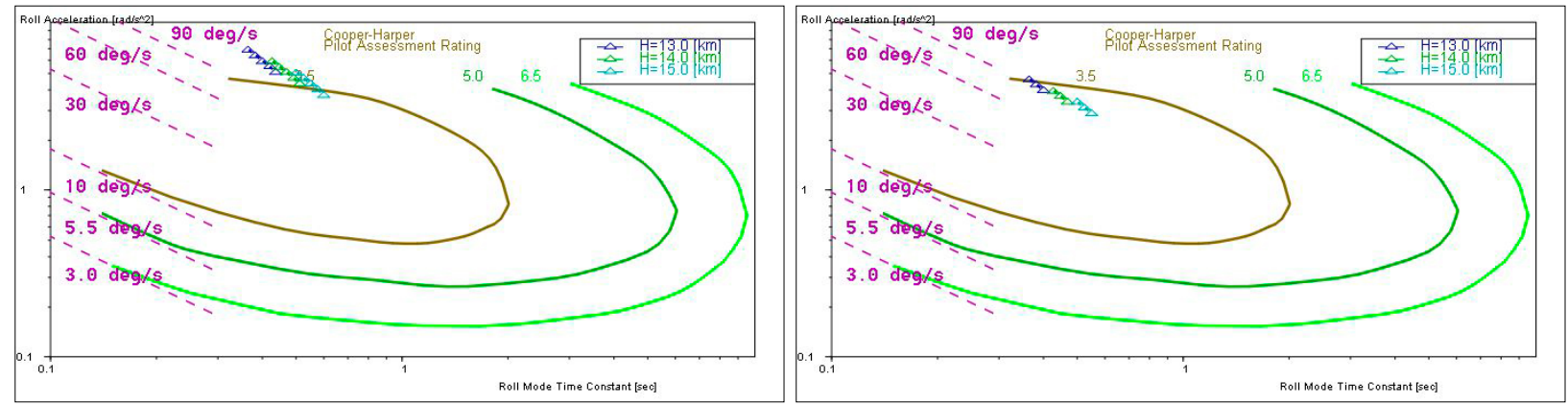

Fig. 18. The Cooper-Harper pilot assessment for configuration No. 1 (on the left) and configuration No. 2 (on the right)

\section{Conclusions}

The analysis of the static and dynamic stability of the Modular Airplane System is described. The results for two positions of the Rocket Plane were presented. The MAS is longitudinally statically stable for both configurations and for all assumed positions of the centre of gravity. However, configuration No. 1 is not dynamically stable. Therefore, configuration No. 2 has been chosen for further analysis of the MAS.

\section{Funding}

This work has been supported by the European Union in the framework of the European Social Fund through the "Didactic Development Program of the Faculty of Power and Aeronautical Engineering of Warsaw University of Technology".

\section{HUMAN CAPITAL} NATIONAL COHESION STRATEGY

\section{EUROPEAN UNION SOUROPEAN}

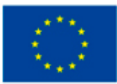

\section{References}

Figat, M.; Galiński, C.; Kwiek, A. 2011. Modular Aeroplane System to space tourism, Progress in Aeronautics 32(1): 24-37.

Figat, M.; Galiński, C.; Kwiek, A. 2012. Modular Aeroplane System. A concept and initial investigation, in Proceedings of ICAS 2012 Conference, 23-28 September 2012, Brisbane, Australia.
Furton Corporation. 2002. Space Tourism Market Study orbital space travel \& destinations with suborbital space travel [online], [cited 10 October 2014]. Available from Internet: http://www.futron.com/upload/wysiwyg/Resources/Reports/Space_Tourism_Market_Study_2002.pdf

Galiński, C.; Goetzendorf-Grabowski, T.; Mieszalski, D. Stefanek, Ł. 2007. A concept of two-staged spaceplane for suborbital tourism, Transactions of the Institute of Aviation 191(4): 33-42.

Goetzendorf-Grabowski, T. 2002. PANUKL potential solver [online]. Software package. Warsaw University of Technology [cited 10 October 2014]. Available from Internet: http://www.meil.pw.edu.pl/add/ADD/Teaching/Software/ PANUKL

Goetzendorf-Grabowski, T. 2008. Flight dynamic analysis of an aircraft within the conceptual stage of the aircraft design, in Proceedings of the VIII RRDPAE Conference, 16-17 October 2008, Brno, Czech Republic.

Goetzendorf-Grabowski, T.; Mieszalski, D.; Marcinkiewicz, E. 2011. Stability analysis using SDSA tool, Progress in Aerospace Sciences 47(8): 636-646. http://dx.doi.org/10.1016/j. paerosci.2011.08.007

Goetzendorf-Grabowski, T. 2008. SDSA - Simulation and Dynamic Stability analysis [online]. Software package. Warsaw University of Technology [cited 10 October 2014]. Available from Internet: http://www.meil.pw.edu.pl/add/ADD/Teaching/Software/SDSA

MGAERO. 2005. MGAERO - a Cartesian Multigird Euler Code for Flow Around Arbitrary Configuration User's Manual, Version 3.1.4, 2005.

MIL-F-8785C. Military specification flying qualities of piloted airplanes, 5 November 1980.

Nelson, R. C. 1998. Flight stability and automatic control. $2^{\text {nd }}$ ed. McGraw-Hill. 


\section{Appendix}

\section{Notation}

AoA - angle of attack [deg.].

C.G. - center of gravity.

CL - lift coefficient.

CMY - pitching moment coefficient.

$\mathrm{dCn} / \mathrm{dBeta}$ - derivative of yawing movement coefficient in respect to sideslip angle.

$\mathrm{Cp}$ - pressure coefficient.

$\mathrm{HN}$ - static stability margin.

$\mathrm{Ma}$ - mach number

MAC - mean aerodynamic chord [m].

MAS - Modular Airplane System.

T- period.

T1/2 - time to half damping.

TAS - true airspeed.

$\xi$ - imaginary part.

$\eta$ - real part. 